\title{
CIGARETTE SMUGGLING: A CASE STUDY OF A SMUGGLING NETWORK IN GREECE
}

\section{INTRODUCTION}

The smuggling of cigarettes has been the focus of a number of journalistic and academic accounts and official reports throughout the world, and has been intertwined with other criminal activities, terrorism ${ }^{2}$, health ${ }^{3}$, minority ethnic groups ${ }^{4}$, and finance. It is estimated that smuggled cigarettes account for $6-8.5 \%$ of the total cigarette consumption ${ }^{5}$, and that for every truckload of cigarettes smuggled into the EU US\$ 1,2 million (about $£ 691,000 /$ EURO 992,000) in taxes are lost. ${ }^{6}$ According to EUROPOL $^{7}$, countries with high taxation on cigarettes are vulnerable to cigarette smuggling however, very interestingly cigarette smuggling may be more prevalent in countries in which cigarettes are cheaper ${ }^{8}$. Spain and Italy for instance, that are two countries of the EU associated with large-scale cigarette smuggling for several decades now. ${ }^{9}$ Greece is a source, transit and destination country for smuggled cigarettes, as well as a country with relatively cheap cigarettes. According to official figures obtained by the Hellenic Coast Guard, in the period 2000-2004 there were 39,941,392 packs of cigarettes seized and the evaded taxes were exceeding EURO 107 million. ${ }^{10}$ In addition, it should be noted that Greece is the top smoking country worldwide in terms of per capita cigarette consumption as well as a country with a relatively large population of smokers that reaches $40 \%$ of the population. ${ }^{11}$

The above have to be viewed within the context of the low 'tax consciousness' among the Greek public, that is believing that the state is a repressive mechanism that

\footnotetext{
1 Lecturer in criminology, School of Social Sciences and Law, University of Teesside, UK. Correspondence: G.Antonopoulos@tees.ac.uk. The author would like to thank the participants of this research, the Hellenic Coast Guard in Piraeus and Patras for the provision of official data, and Klaus von Lampe, John Winterdyk, Dick Hobbs, and Georgios Papanicolaou for their comments and suggestions on earlier drafts of this paper.

2 D. Coker, 'Smoking May Not Only Be Hazardous To Your Health But Also To World Political Stability: The European Union's Fight Against Cigarette Smuggling Rings That Benefit Terrorism', 11 European Journal of Crime, Criminal Law and Criminal Justice,(2003), pp.350-376

${ }^{3}$ L. Joossens, F.J. Chaloupka, D. Merriman and A. Yurekli, 'Issues in the Smuggling of Tobacco Products'. In P. Jha and F. Chaloupka (eds), Tobacco Control in Developing Countries. (pp.393-406) (New York, 2000)

${ }^{4}$ EUROPOL, 2003 European Union Organised Crime Report. (Luxembourg, 2003)

${ }^{5}$ O, Shafey, V. Cokkinides, T.M. Cavalcante, M. Teixeira, C. Vianna and M. Thun, (2002) 'Case Studies in International Tobacco Surveillance: Cigarette Smuggling in Brazil', 11 Tobacco Control, (2002), pp.215-219

${ }^{6}$ D. Campbell, 'Lost in Transit', 369 New Internationalist, (2004)

${ }^{7}$ EUROPOL (2003), loc. cit

${ }^{8}$ L. Joossens and M. Raw, (2004) 'How Can Cigarette Smuggling Be Reduced?', 321 British Medical Journal, (2004), pp.947-950

${ }^{9}$ K. von Lampe, Provisional Situational Report on Trafficking in Contraband Cigarettes. Sixth Framework Programme (2005)

${ }^{10}$ Hellenic Coast Guard, Cigarette smuggling-Unpublished Statistics. (2005)

${ }^{11}$ European Communities \& WHO, Highlights on Health in Greece. (Copenhagen, 1998)
} 
takes a significant part of their income ${ }^{12}$, as well as the fact that the informal economy in the country that accounts for up to 30 per cent of the GDP, is the largest informal economy in Europe ${ }^{13}$. Consequently, there may be a case that cigarette smuggling is supported not only by the smokers, who buy black market cigarettes but also supported 'morally' by the smoking population. Finally, it is the 'treatment' cigarette smuggling, and especially street-selling of smuggled cigarettes, receives from the police. It is suggested that there is a tolerant environment to cigarette smuggling in Greece that, in contrast to other contexts and commodities' trades (e.g., cocaine trafficking in the Netherlands, see Zaitch, $2002^{14}$ ), refers to both the general climate to the particular trade and law enforcement. For all the above, Greece is an important context for the study of cigarette smuggling. The topic however, has been relatively neglected by the academic community, as we only have a superficial account of cigarette smuggling - among other criminal activities - by Albanian organised crime groups in Greece ${ }^{15}$, and a small account of the phenomenon in a general textbook on tobacco and smoking ${ }^{16}$.

According to Joossens ${ }^{17}$, there are basically two ways of smuggling large quantities of cigarettes: a) bootlegging: buying an amount of cigarettes that exceeds custom regulations, and b) large-scale smuggling. Von Lampe ${ }^{18}$ comes to add another way of supplying cigarettes to the black market, namely counterfeiting. In this study the focus is on the second way of smuggling, and this article intends to provide a detailed case study of a cigarette smuggling network operating in Greece. Case studies have been used in other projects to throw light onto the structure and workings of 'organised' crime such as this by Natarajan ${ }^{19}$ and Pearson and Hobbs ${ }^{20}$. The aim of the study is broken down into four objectives:

1. to provide an account of the structure of the particular network,

2. to provide a description of the 'actors' involved in the particular network,

3. to provide an account of the ways the particular network obtains and stores smuggled cigarettes, and finally

4. to provide an account of the introduction of smuggled cigarettes into the market and their distribution by the particular network.

In this article we are not in the position to provide an account of the social organisation of the cigarette smuggling business in the country, as we do not possess such a large amount of information. What we do however, is to provide information

\footnotetext{
${ }^{12}$ I.S. Vavouras and N.H. Karavitis, 'To Provlima tis Paraoikonomias stin Ellada: Ektasi, Epiptoseis, Politiki Antimetopisis' [The Problem of Para-economy in Greece: Extent, Impacts, Policies]. In A.D. Kintis (ed.) To Paron kai to Mellon tis Ellinikis Economias. [The Present and the Future of the Greek Economy]. (pp.125-136) (Athens, 1997)

${ }^{13}$ The Economist, 'Economic Indicators', The Economist, (2001), 3 February, p.136

${ }^{14}$ D. Zaitch, 'From Cali to Rotterdam: Perceptions of Colombian Cocaine Traffickers on the Dutch Port', 38 Crime, Law and Social Change, (2002), pp.239-266

${ }^{15}$ G. A. Antonopoulos, 'Albanian Organised Crime: A View from Greece', 19(77) Crime and Justice International, (2003), pp.5-9

${ }^{16}$ S.C. Dodopoulos, Kapnos \& Kapnisma [Tobacco \& Smoking]. (Athens, 2004)

${ }^{17}$ L. Joossens, Smuggling and Cross-Border Shopping of Tobacco Products in the European Union: A Report for the Health Education Authority. (London, 1999)

${ }^{18}$ K. von Lampe, (2005) loc.cit.

${ }^{19}$ M. Natarajan, 'Understanding the Structure of a Drug Trafficking Organisation: A Conversational Analysis. In M. Natarajan and M. Hough (eds) Illegal Drug Markets: From Research to Prevention Policy. (pp.273-298) (Monsey, NY, 2000)

${ }^{20}$ G. Pearson and D. Hobbs, 'King Pin? A Case Study of a Middle Market Drug Broker', 42 The Howard Journal of Criminal Justice, (2003), pp.335-347
} 
on the social organisation of $a$ smuggling network, which our informants were involved in 2002 and 2003, and have knowledge of.

\section{METHODOLOGY}

Researching organised crime is a potentially risky endeavour. Thus researchers usually use official data, which - although they are extremely valuable they do not provide an integrated approach to the topic ${ }^{21}$ as they 'ignore' the "reality of the offenders" ${ }^{\prime 2}$. In this study a strategy other than the official data has been utilised. This paper is the product of a series of interviews with three retired Kurdish cigarette smugglers. These individuals included 1 pusher and 2 street-sellers (we provide a detailed account of what a pusher and a street-seller are at a later stage). Through contacts we initially met the pusher, who then led us to the two street-sellers, who had worked for him when in Greece. These interviews, which were conducted in a series of occasions and as free-flowing conversations with the participants between September 2004 and December 2004, are part of an ethnographic study with the Kurdish community in a town of the North-East of England. The ethnographic study did not start with the aim of identifying the social organisation features of a cigarette smuggling network but those of migrant smuggling.

This paper is only a part of the ethnographic study, and some other data and information from this research have been used in accounts of migrants smuggling ${ }^{23}$. The interviews for the current study were almost exclusively conducted in Greek, and this was due to the participants' extended (illegal) residence in Greece.

The validity of the participants' accounts is an issue that warrants at least a comment. There may be instances in which participants exaggerate and glorify their deeds or instances in which there are unclear accounts. We attempted to prevent invalid accounts on the part of the participants by many times repeating questions over the course of the particular research, and by verifying accounts against those of the other 'members'/nodes of the cigarette smuggling network. During this crossreferencing process the degree of details was such as to allow us to accept the accounts as valid.

\section{THE SOCIAL ORGANISATION OF THE CIGARETTE SMUGGLING NETWORK}

\subsection{Structure of the cigarette smuggling network}

References in the Greek media to the Mafia and/or the Cartel $^{24}$ when it comes to organised criminal activities including the smuggling of cigarettes creates the

\footnotetext{
${ }^{21}$ P. Rawlinson, 'Mafia, Methodology, and 'Alien' Culture'. In R. King and E. Wincup (Eds.) Doing Research on Crime and Justice. (pp. 351-362.) (New York, 2000)

${ }^{22}$ D. Hobbs, 'Researching Serious Crime'. In R. King and E. Wincup (Eds.) Doing Research on Crime and Justice. (pp. 153-182) (New York, 2000)

${ }^{23}$ See G. A. Antonopoulos and J. A. Winterdyk, 'Smuggling of Migrants in Greece: An Examination of Its Social Organisation', 3(4) European Journal of Criminology, (forthcoming, 2006)

${ }^{24}$ See for example D. Tzathas, and P. Giogiakas, 'I Mafia ton Tsigaron' [The Mafia of Cigarettes], $T a$ Nea, (1997), 5 June; T. Argyrakis, T., 'I Ellada Katafygio tis Rosikis Mafias' [Greece is the Refuge of the Russian Mafia], Eleftheros Typos, (1998), 22 December, p.23; Ethnos, 'I Mafia ton Polytelon I.X' [The Mafia of the Luxury Cars], Ethnos, (2001), 18 July, p.15
} 
impression that this enterprise (as well as other illegal enterprises) is controlled by strong, closed, rigid, hierarchical, and extremely powerful Mafia-type organisations. This representation, although it is beneficial to law enforcement and the state ${ }^{25}$ and to the media themselves due to the attractiveness of an issue/entity like the $\mathrm{Mafia}^{26}$, is to a large extent a misunderstanding. ${ }^{27}$ Contrary to this misrepresentation, the important term/structure/entity here is the network. Networks are fluid thus easily adaptable to the new operational environments ${ }^{28}$ and forms of social control ${ }^{29}$. Networks may not be static but, in our opinion, neither they continuously change nor are they perpetually fluid $^{30}$.

In this study, although specific groups within the network are ethnically homogeneous, the particular network is ethnically heterogeneous. This contributes to the flexibility of the network. As Pearson and Hobbs suggest, "too much reliance on [the] ...more traditional forms of trust relation can become a liability, since an exclusive dependence on embedded ties can trap the firm in a closed network that would inevitably choke itself". ${ }^{31}$ Of course, Greeks are also heavily involved in the workings of the network in a variety of ways as we shall show at a later stage. The cigarette smuggling network is composed of smaller local smuggling 'groups' and/or individuals that operate in cooperation (and sometimes in competition), and connect to each other through individuals, who are reciprocally linked in some way or another $^{32}$, strongly or weakly, to more than one individuals and groups ${ }^{33}$. Although the global implications of cigarette smuggling, and organised crime in general, are clear $^{34}$ these groups largely operate on a local/regional level. As Hobbs has noted, "networks are the media through which ...groups move between the local and the global". 35

Technological advancements, and specifically mobile phones, contribute to the regular communication between individuals and consequently between groups and networks, and the possible expansion of the network ${ }^{36}$. All participants in the current study, for instance, had more than one mobile phones, one of which was specifically

\footnotetext{
${ }^{25}$ T. Naylor, Wages of Crime: Black Markets, Illegal Finance and the Underworld Economy. (Revised edition) (Ithaca, N.Y., 2004)

${ }^{26}$ K. von Lampe, 'Not a Process of Enlightenment: The Conceptual History of Organised Crime in Germany and the United States of America', 1(2) Forum on Crime and Society, (2001), pp.99-116

${ }^{27}$ See C. Fijnaut and L. Paoli (eds.), Organised Crime in Europe: Concepts, Patterns and Control Policies in the European Union and Beyond. (Dordrecht, 2004)

${ }^{28}$ P. Williams, 'Organising Transnational Crime: Networks, Markets and Hierarchies'. In P. Williams and D. Vlassis (Eds) Combating Transnational Crime: Concepts, Activities and Responses. (pp. 57-87). (London, 2001); J. S. MacIllwain, 'Organised Crime: A Social Network Approach', 32(4) Crime, Law and Social Change, (1999), pp.301-323

${ }^{29}$ V. Ruggiero, 'Global Markets and Crime'. In M. Beare (ed.) Critical Reflection on Transnational Organised Crime, Money Laundering and Corruption. (pp.171-182) (Toronto, 2003)

${ }^{30}$ G. Lovink and N. Rossiter, 'Dawn of the Organised Networks', 5 Fibreculture, (2005). Available online at: http://journal.fibreculture.org/issue5/lovink rossiter.html, accessed on 14 March 2006

${ }^{31}$ G. Pearson and D. Hobbs, Middle Market Drug Distribution. Home Office Research Study 227 (London, 2001) p.28

${ }^{32}$ See D. Hobbs, 'Professional Crime: Change, Continuity and the Enduring Myth of the Underworld', 31(1) Sociology, (1997), pp.57-72

${ }^{33}$ See G. Bruinsma and W. Bernasco, 'Criminal Groups and Transnational Illegal Markets', 41 Crime, Law and Social Change, (2004), pp.79-94

${ }^{34}$ See Fijnaut and Paoli (2004), loc. cit.

35 D. Hobbs, 'Going Down the Glocal: The Local Context of Organised Crime', 37 The Howard Journal of Criminal Justice, (1998), pp.407-422, p.419

${ }^{36}$ N. Coles, 'It's Not What You Know - It's Who You Know That Counts: Analysing Serious Crime Groups as Social Networks', 41 British Journal of Criminology, (2001), pp.580-594
} 
used for 'business'. Their business phone number was known only by other people involved in the business or by (known) customers.

There are three levels in the actual cigarette smuggling network that are identified in this study, similar to those identified by von Lampe ${ }^{37}$ : Upper level, middle level, and street level. But as will be shown later in this paper there are some 'nodes' of the network that cannot be categorised in any of the levels really primarily because of the nature of their activities in relation to the cigarette smuggling business (e.g., corrupt public officials).

Within the context described above, there is a division of duties, although many times the duties that each member has to carry out may change. There is also a case, just as with other trades (e.g. migrant smuggling) ${ }^{38}$ in which a member of a smuggling group may have more than one duty. However, there are some 'roles' within each group that remain stable over time:

a) Wholesaler: The wholesaler has a 'managerial' position in the whole business. In this case study the wholesaler is a Russian with a number of legitimate businesses in the country, Russia and Germany, and with connections in the country of production of cigarettes, transit countries as well as Greece. The particular Russian has very successfully invested money obtained from illicit trades involving cigarette smuggling into legitimate businesses in the aforementioned countries. In this network the wholesaler acts as the 'leader' of the network. However, the fact that there is a 'leader' does not of course mean that "conspiracies and mega-hierarchies"39 exist. The particular Russian wholesaler is nothing near a Godfather-like figure.

b) Procurers: The procurers in this network are primarily Greeks owning legitimate businesses, who buy large quantities of cigarettes from Greek tobacco companies with the intention to export and sell them in Bulgaria, and then forward it (wholly or partly) to the wholesaler and/or the pusher. Non-Greek procurers, strongly tied to the wholesaler only, residing in countries other than Greece, and specifically countries of the former Soviet Union, are also present. It is hypothesised that they are some of the links between the network presented in this study and other networks.

c) Pushers: These are individuals who are known to the wholesaler and (some of) the Greek procurers, they are considered trustworthy, and have the responsibility of introducing the smuggled cigarettes to the market. van Duyne ${ }^{40}$ refers to these individuals as the intermediaries. Some pushers do not know of other pushers. Some however, may have a very close relationship. For instance, one of the evenings spent with one of the participants another pusher, a Russian one currently working in Greece, gave him a call and had a quite lengthy and warm phone chat (in Greek). They would both send gifts to each other in the form of cigarettes, money, house ornaments etc. It is not an essential requirement for the pusher to have been previously involved in a 'managerial' position in some other smuggling business, although the Kurdish pusher interviewed was involved in the

\footnotetext{
${ }^{37}$ K. von Lampe, 'The Illegal Cigarette Market in Germany: A Case Study of Organised Crime'. Paper presented at the $1^{\text {st }}$ annual meeting of the European Society of Criminology, Lausanne, Switzerland, (2001), 6 September

${ }^{38}$ See Antonopoulos and Winterdyk, loc. cit

${ }^{39}$ P. Klerks, (2001) 'The Network Paradigm Applied to Criminal Organisations: Theoretical Nitpicking or a Relevant Doctrine for Investigators? Recent Developments in the Netherlands', 24(3) Connections, (2001), pp.53-65, p.57

${ }^{40}$ P.C. van Duyne, 'Organising Cigarette Smuggling and Policy Making, Ending Up in Smoke', 39

Crime, Law and Social Change, (2003), pp.285-317
} 
smuggling of video-cassettes from Iraq into Iran in the 1990s. However, the pushers usually start as street-sellers and, based on their abilities to manage and sell large quantities of cigarettes as well as on contacts, possibilities of upward mobility within the network/market appear. For instance, another pusher in the particular network was working as a street-seller for 4 months before he was given the opportunity to climb the ladder of the cigarette smuggling business.

d) Street-sellers. These are individuals primarily drawn from the migrant community in the country, which serves as a reliable pool for low level employees in illicit markets ${ }^{41}$. The vast majority of the street-sellers of the particular network examined come from the community of migrants from the former Soviet Union (e.g., Russian, Ukrainian, Georgian, and Armenian migrants), including a number of middle-age women. There is also a number of Kurdish street-sellers. The reason for this is that the second-level cigarette smugglers identified in this network, the pushers, are of Soviet and Kurdish background, who employ people of the same ethnic origin, because of the features like common language, culture and experiences that results in a smoother working of the network. As Lupsha ${ }^{42}$ suggests "if a group speaks the same language, has the same village roots, possesses the same myths and cultural norms then it can function as a unit with greater trust and understanding". This does not mean, of course, that there are strong ethnic tights/seals in the network. In some instances street-sellers of ethnic origin other than Soviet and Kurdish are employed (e.g., Bulgarians, Romanians, and Albanians), and it is not uncommon for Greeks, primarily Greek Roma to be involved in street selling. Each pusher employs about 10-15 street-sellers at any given time, who are paid about EURO 30 a day irrespectively of the sells. The Kurdish pusher often changes workers. Street-sellers of Kurdish origin are 'recycled' in a high rate. This is inevitable, not due to any criminal justice variables, but because the vast majority of Kurdish migrants are highly mobile, as they view Greece primarily as a transit country to countries of western Europe ${ }^{43}$; and particularly the United Kingdom and Germany being the main destination countries. Despite the fact that Kurdish migrants are involved in cigarette smuggling, and especially the highly visible street-level smuggling, official reports totally ignore their involvement in this trade. $^{44}$

e) Scouters/Look-Outs: Scouters/look-outs are basically in-and-around the areas in which the street-selling of smuggled cigarettes takes place. They are there to warn/alert street-sellers about the presence of the police in the area, and especially known (to them) non-uniformed police. In respect to the Kurdish part of the network described in this study, it is worth noting that because the word police is pronounced in the same in Kurdish, the word used by the scouters/lookouts to warn the street-sellers is pakhla, which literally refers to a form of a traditional Kurdish food. This brings in mind the phrase people in the deprived areas in Bourgois' research ${ }^{45}$ use for police patrol cars, namely ugly cars.

\footnotetext{
${ }^{41}$ See Antonopoulos (2003) loc. cit.

${ }^{42}$ P. Lupsha, 'Individual Choice, Material Culture and Organised Crime', 19(1) Criminology, (1981), pp.3-24

${ }^{43}$ A. Papadopoulou, 'Kurdish Asylum Seekers in Greece: The Role of Networks in the Migration Process'. Paper presented at the UNU/WIDER Conference on Poverty, International Migration and Asylum, Helsinki, Finland, (2002), 27-28 September

${ }^{44}$ See MPO, Annual Report on Organised Crime in Greece, 2004. (Athens, 2005)

${ }^{45}$ P. Bourgois, 'Just Another Night in a Shooting Gallery', 15(2) Theory, Culture and Society, (1998), pp.37-66
} 
f) The 'House Guards': The 'house guards' have the responsibility of guarding the houses, rooms, etc. at the central business district and transitional zone in Athens (usually) rented by the pushers or by Greeks connected in any way with the pushers (e.g., wives and/or girlfriends) that used as storing places for boxes with cigarettes before they are distributed to the street-sellers or sold to some customers directly. The house guards may be recruited specifically for this task but the author came across Kurdish migrants who have no accommodation, and they are provided a place to stay under the requirement to watch the merchandise, and open the door to known street-sellers only. House guards are also paid about EURO 30 a day. The 'house guards', as well as the street-sellers and the scouters/look-out are recruited from the migrant community since they are socially and very importantly economically marginalised. As one of the informants suggested in relation to the Kurdish people involved in the trade:

"When Kurdish people come to Greece they have no job, they have no money, they have nothing... when I give them some work with cigarettes I help them. It is a big help you know...”.

g) Legitimate shop owners: They are almost exclusively Greeks, who own a shop in or around the street-selling area and 'operate' as a quick 'refuelling' point for street-sellers and/or a place of quickly 'hiding' the smuggled cigarettes when police are very close to the street-selling point.

h) Thieves/Burglars: Thieves and burglars participating in this network are 'professionals', who feed the pushers with cigarettes they steal from large warehouses of cigarettes destined for the legal cigarette market. Technically they do a job similar to the procurers but with a much smaller frequency. They are usually drawn from the migrant community from the former Soviet Union, and they are strongly tied with the Russian pushers. As the informants suggested there were three groups in Menidi, in the greater Athens area, that were doing this job in the early 2000s.

i) Drivers/Captains: As reported by the participants, the drivers and captains of ships have the responsibility of transporting quantities of cigarettes into Greece. They are usually individuals employed legally as truck drivers and/or captains and either transport cigarettes as the main product or concealed in their legal merchandise. The truck drivers are Greeks whereas the captains tend to come from Greece, Russia and Ukraine.

j) 'Protectors': These are individuals, who engage in the protection of the interests of the cigarette smuggling business from Albanian and Russian extortion gangs. In the current research the author did not come across any protectors coming from the Kurdish community but from the community of migrants from the former Soviet Union. It is not that the Kurdish street-sellers are not in need of some form of protection against extortion and/or robbery. Quite the opposite; however, a large number of Kurdish migrants residing (and hanging around) in these areas of the city where street-level cigarette smuggling takes place, and the strong relationship between the members of the Kurdish community, make intervention by Kurdish bystanders almost certain. Many times there are fights among groups from the former Soviet Union with conflicting interests (not only cigarette-related) in areas such as Menidi, a suburb of Athens, where not only is there a high concentration of migrants from the former Soviet Union but also places for the storing of large quantities of cigarettes. While fighting in the area 
of street-selling is extremely infrequent, it does happen from time to time. It is hypothesised that the general absence of fighting at the street-selling is usually the result of the reluctance on the part of the actors of the network to attract police attention and jeopardise the market. The 'protectors' are nodes of the network that are not affected by the dynamics of the illegal market per se. ${ }^{46}$ They, and violence in general, have a peripheral role in the actual cigarette smuggling business. In relation to this Hobbs ${ }^{47}$ has argued the dominating force for such businesses to be the market "rather than some cosy, familiar macho world of hard men ...". Nevertheless, the 'protectors' are an integral part of the whole picture.

k) Corrupt public officials: The corrupt public official "is a vital node in the criminal network" ${ }^{48}$, and the cigarette smuggling network presented in this article is, of course, no exception. There were numerous references to customs officers employed in the borders with Bulgaria, who were bribed to allow for the importation of smuggled cigarettes in the country (among other 'commodities'). In addition, the participants in this research verified in numerous instances that police officers and coast guards were bribed primarily to 'turn a blind eye' to allowing storing places for large quantities of smuggled cigarettes to exist or when coming across larger quantities of smuggled cigarettes by sea. On the street-level however, police officers were not bribed to 'turn a blind eye' to the distribution of cigarettes because, as noted earlier, the police were very tolerant to the illegal cigarette street market. In fact, on the street-level corrupt police officers were exploiting their position to exert amounts of money from streetsellers.

The whole network described in this study is graphically presented in Figure 1. Because, apart from nodes, networks are also about ties, the author will attempt to provide graphically and tentatively the strength of ties between the nodes (actors) in this network. In this attempt he adopts Granovetter's ${ }^{49}$ view, namely that the strength of ties depends on intimacy and nature of interaction, emotional intensity, time spent and exchange of services among 'members' of a network or a combination of all the above. The reader should also be aware however, that each node does not have the quantity of one actor.

\footnotetext{
${ }^{46} \mathrm{~K}$. von Lampe, 'The Trafficking in Untaxed Cigarettes in Germany: A Case Study of the Social Embeddedness of Illegal Markets'. In P.C. van Duyne, K. von Lampe and N. Passas (eds) Upperworld and Underworld in Cross-Border Crime. (pp.141-161) (Nijmegen, 2002)

${ }^{47}$ D. Hobbs, Bad Business. (Oxford, 1995), p.27

${ }^{48}$ Williams (2001), loc. cit. p.76

${ }^{49}$ M.S. Granovetter, 'The Strength of Weak Ties', 78(6) American Journal of Sociology, (1973), pp. $1360-1380$
} 
Figure 1. Structure of the Cigarette Smuggling Network

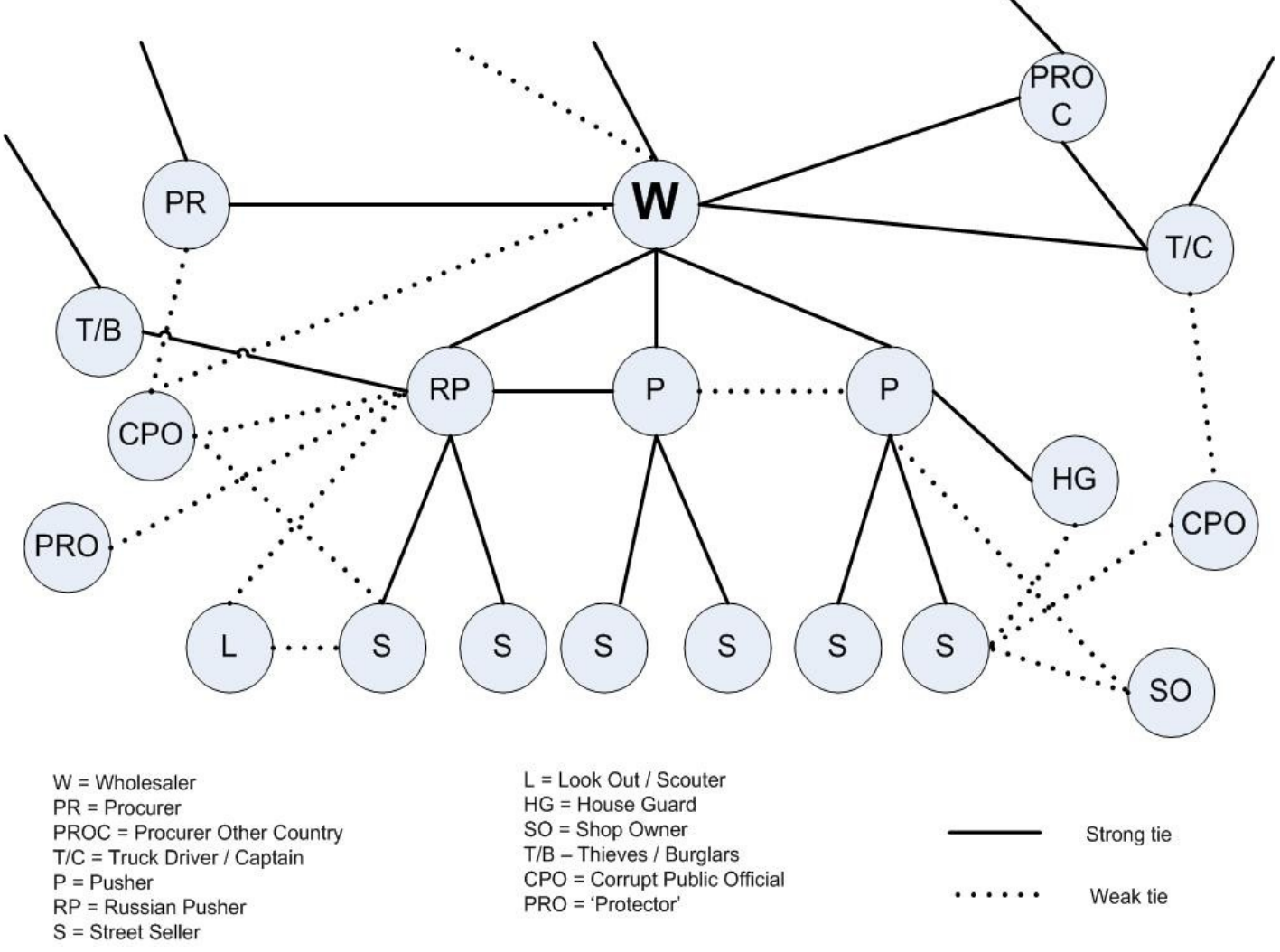

As mentioned earlier the Wholesaler acts as the 'leader' of the particular network in the sense that the whole network evolves around him. The Wholesaler has strong ties with the Procurers, who provide large quantities of cigarettes and the Truck Drivers/Captains, who have the responsibility of transporting these quantities. He also has strong ties with the Pushers, who are responsible for introducing the merchandise into the market. On the other hand the ties between the Wholesaler and the Corrupt Public Officials are not strong, they are not continuous, they are sporadic, and serve as a lubricant for the workings of the market at all levels of cigarette smuggling. Consequently, the Corrupt Public Officials are also weakly tied to the Procurers, the Pushers, and the Street-Sellers as well as the Truck Drivers/Captains. Some Pushers have strong ties with other Pushers; however, this is not always the case. All Pushers are strongly tied to the Street-Sellers they work with. Moreover, the Russian Pushers are strongly tied to the Thieves/Burglars, weakly tied to the Protectors and the Look Outs/Scouters, and the Pushers (including the participants of this study) are weakly tied to the Look Outs/Scouters and the Shop-Owners, and strongly tied with the House Guards. Finally, the Street-Sellers are weakly tied to the Shop Owners, the House Guards, and the Look Outs/Scouters.

It should be noted that strong and weak ties in this figure generally refer to market/business and not personal, ethnic or other ties. As it is obvious in this figure some lines extent but do not link to any actors. This is to show that the network presented in this article may be linked to other network(s) "through particular actors, 
who serve as "bridges""50. These networks are however, beyond the scope of this study. The fact that some individuals are weakly linked to other individuals within this network does not, of course, mean that they are not important. Coles, citing his thoughts on Granovetter's article, suggests "it is those individuals, who have weak ties to others in other groups, who provide the links for the chains along which information can pass" $" 51$.

The recruitment of members for this cigarette smuggling network is an extremely interesting feature. The particular network has evolved around the wholesaler. On the level of the pusher, membership is tightly restricted and depends either on contacts and on previously presented 'credentials' and experience or on trust. The first of the informants, who worked as a pusher in the particular cigarette smuggling network, was recruited by one of the Russian pushers involved in the network. It is hypothesised that this recruitment was a way for the Russian pusher to exploit Kurdish migrants on the street in specific areas of central Athens, and integrate them through the Kurdish pusher into the network. On the street level however, recruitment is rather lax trust wise. The two street-sellers providing information for the current study are Kurdish, who were recruited by the Kurdish pusher.

\subsection{Obtaining and storing smuggled cigarettes}

There are a number of ways in which the particular smuggling network obtains cigarettes to distribute into the black market. These involve:

a) Stealing cigarettes from warehouse where they are stored to be introduced into the legal market. The stealing of cigarettes, which is performed by the thieves/burglars, as mentioned in the previous subsection, happens in a small frequency, and is certainly not the most popular way of obtaining cigarettes for the black market.

b) Importation of smuggled cigarettes from Ukraine and Russia by ship. The fact that a large amount of cigarettes come from the former Soviet republics (and given that the wholesaler of this network as well as two pushers are Russian) shows that ethnic links and connections are commercially exploited just as in the case of drug trafficking. ${ }^{52}$ Shipped cigarettes are brought into Greece through Greek ports and specifically through the ports of Piraeus and Thessaloniki. Cigarettes are stored in containers, and may be concealed by other, legal merchandise. In a number of cases cigarettes are imported in Greece with small sea vessels via specific locations in the prefecture of Attica.

c) Importation of smuggled cigarettes from Bulgaria by truck. There are however, two different ways of cigarette smuggling by truck. The first involves cigarettes produced in Bulgaria that are illegally forwarded to Greece. The second way is by Greek procurers going directly to tobacco companies in Greece and requesting to buy a large amount of cigarettes (usually a truckload) in order to export them to Bulgaria. The necessary papers

\footnotetext{
${ }^{50}$ K. von Lampe, 'Criminally Exploitable Ties: A Network Approach to Organised Crime'. In E.C. Viano, J. Magallanes and L. Bridel (eds) Transnational Organised Crime: Myth, Power, and Profit. (pp.9-22) (Durham, N.C., 2003), p.14

${ }^{51}$ Coles (2001), loc. cit., p.587

${ }^{52}$ See Pearson and Hobbs (2001) loc. cit.. It is also interesting to note that the packs of cigarettes the participants were sent from the Russian pusher in Greece, and which were smuggled in/through Greece, had health signs in Russian. This shows the intended market of introduction and distribution.
} 
are issues, the truck gets out of Greece and returns back to Greece supposedly without merchandise. The smuggled cigarettes are then sold to the 'wholesaler' of the smuggling network described in this paper, and through the pushers are brought into the market. Needless to say corrupt public official and specifically customs officers tend to be involved in the whole process.

According to the participants, the major brands obtained in the above ways by the smuggling network presented in this study include the Greek Assos Filtre, Assos International and Karelia, and Pall Mall, Silk Cut, Winston and the most popular brand, Marlboro. Rather uncommonly some unknown Russian/Soviet brands were also obtained. Large quantities of cigarettes are stored by the network, as mentioned earlier, in houses, rooms or other storing spaces rented by the pushers (or by Greeks linked to the pushers). Quantities of about 1-2 boxes (50-100 cartons/500-1000 packs of cigarettes) are also stored in shops (of any type) owned primarily by Greeks in and around the area of street-selling. These shops constitute, as mentioned earlier, a point for quick 'refuelling' for the street-sellers known to the shop owner.

\subsection{Distributing the Smuggled Cigarettes}

Just as with other illicit markets there is an open and a closed market. Open markets are those formed on the street (and other public places such as squares), where the street-seller awaits to be approached by customers or approaches prospective customers. Contrary to some illicit markets that take place out of sight of the general public, cigarette smuggling is in some places highly observable. For instance, in the central business district of Athens it is not uncommon for the passersby to observe street-sellers and be approached by them.

The second form of this illicit market is the hidden, closed market, which does not take place on the street, and is basically arranged by the pusher or the street-seller and the customer. The customers however, in contrast to the open market, have to be already introduced, either by another pusher or by an established and trusted customer.

"...no one goes alone [to buy cigarettes in the closed market]... they all go with someone who has already bought cigarettes..."

'Good' and trusted customers many times are aware of the places in which large quantities (e.g. houses, rooms, storing places etc.) or medium quantities (e.g., shops around the area of street selling) of smuggled cigarettes are kept. Sometimes the customers in the closed market may even be introduced by a street-seller. As the Kurdish pusher interviewed noted:

"On the street...when a Kurdish guy [street-seller] is approached by a customer, who says 'I want 100 cartons' ... he brings the customer to me".

Rather surprisingly, no great caution is taken in such cases. In contrast to the open market that, as mentioned earlier, is based on specific geographic areas of the city, the closed market most of the times operate in a variety of areas. There are instances, for example, in which a pusher will supply customers who need large quantities of cigarettes, and who live in various areas in the greater Athens area. For a few known and good customers selling may even take place by telephone order. According to information obtained by the participants, every pusher sells (either in the closed or in 
the open market through the street-sellers or not) 15 boxes of cigarettes (750 cartons/7,500 packs) on average every day. Each box, which is bought EURO 350 (about $£ 242 / \mathrm{US} \$ 422$ ) by the pusher, is sold for about EURO 550 (about $£ 380 /$ US\$ $663)$. Each pack of cigarettes, especially from the popular brands, is usually sold half the price of a pack sold in the legal market.

\section{DISCUSSION/CONCLUSION}

The aim of this article was to describe a cigarette smuggling network in Greece. It is likely that similar networks exist, which may be connected to the network presented in this study in a variety of ways. In this research it is identified that:

- There are specific duties/roles in the particular cigarette smuggling network.

- Each 'actor' of the network is tied to other 'actors' strongly or weakly.

- The network initially evolves around the 'wholesaler'. On the middle-level membership is tightly restricted and depends on variety of factors such as contacts, previously presented 'credentials', experience in the (cigarette smuggling) business and trust. On the street level however, recruitment is not restricted.

- Cigarettes to be smuggled are obtained in a variety of way including stealing of cigarettes or importation of cigarettes from countries of the former Eastern bloc. In some cases cigarettes destined for the Bulgarian market may even be obtained from Greek tobacco companies.

- Large quantities of cigarettes are stored by the network in houses, rooms or other storing places rented by the pushers or by Greek individuals linked to the pushers. Smaller quantities of 1-2 boxes (50-100 cartons/500-1000 packs of cigarettes) are also stored in legitimate shops around the area of street-selling.

- Smuggled cigarettes are distributed in an open (street, public place) and a closed market. Each pusher introduces 15 boxes of smuggled cigarettes (750 cartons/7,500 packs) in the market on average every day.

Apart from the issues associated with the social organisation of the particular cigarette smuggling network there are, in the author's opinion, two additional important issues that arise from this study. The particular methodological strategy has enabled the author to provide an account of a cigarette smuggling network in Greece that would be quite different if he relied exclusively on official data and sources that "may refer more to contextual variables than to the nature and extent of criminal networks" The sometimes misleading accounts that official sources can provide - if they are used exclusively and are not backed up by additional sources of information - is exemplified in the case of cigarette smuggling. In the Annual Report on Organised Crime in Greece for 2004 the Greek Ministry of Public Order suggests that "from the cases that were examined it appears that Greece mainly constitutes a transit and not the destination country for smuggled cigarettes" ${ }^{, 54}$, with quantities of smuggled cigarettes being destined for the black markets of North European countries such as the United Kingdom, where the tax is high compared to other countries ${ }^{55}$. Although, Greece is indeed a transit country for smuggled cigarettes, this perception coincides

\footnotetext{
${ }^{53}$ K. von Lampe, 'Making the Second Step Before the First: Assessing Organised Crime. The Case of Germany', 42 Crime, Law and Social Change, (2004), pp.227-259

${ }^{54}$ MPO (2005) loc. cit., p. 19

${ }^{55}$ MPO (2005) loc. cit.
} 
with other official perceptions relating to the link between high taxes and prevalence of smuggling. In addition, the research has shown that Kurdish migrants are involved in cigarette smuggling, although law enforcement personnel do not perceive them as an ethnic group involved in organised criminal activities.

What we also think as an important issue stemming out of this research is the socio-economic position of migrants/ethnic groups in Greece, and the role this plays in their involvement in cigarette smuggling (among other criminal activities). von Lampe $^{56}$ informs us that the street-level cigarette smuggling in East Germany was taken over by Vietnamese guest workers, who were unemployed as a result of the huge industrial and economic restructuring that occurred in the early 1990s. Similarly, some members of the Aboriginal communities in Canada are involved in cigarette smuggling because the opportunities for legitimate employment are limited ${ }^{57}$. The rigid legal framework of migration in Greece since the early 1990s has created the fertile ground for the criminalisation of migrants, through their exclusion, their positioning into the margins of the Greece society, the inability to formulate social bonds between the migrants and the Greek society, thus creating all the necessary conditions for the entrance of migrants to criminal activities including the smuggling of cigarettes. The cigarette smuggling business offers a large number of migrants some employment and income.

Hopefully, the current research that refers to a geographic context generally neglected by the criminological enterprise will add to the existing literature on cigarette smuggling in particular and organised crime in general by contributing to the construction of "a typology of different constellations of organised crime" ${ }^{\text {. }}$. Based on the findings of this study, it is recommended:

- Research that will assist in a better understanding of the dynamics of cigarette smuggling and the forces that move/drive/promote/stimulate it including any "regulatory asymmetries" 59 .

- Additional research on the social organisation of the cigarette smuggling business in the country. Cigarette smuggling causes - among other phenomena - great difficulties in the attempts to provide an analysis of smoking prevalence and pattern in a country, and in consequence ways of reducing smoking and improving health. ${ }^{60}$

- Research on the role the social and economic marginalisation of migrants plays in the involvement of migrants in cigarette smuggling in Greece. Although minority ethnic groups members are not found in illegal cigarette markets in some contexts (e.g., the Netherlands) ${ }^{61}$, this is certainly the case in Greece.

\footnotetext{
${ }^{56} \mathrm{~K}$. von Lampe, 'Organising the Nicotine Racket: Patterns of Cooperation in the Cigarette Black Market in Germany'. In P. van Duyne, K. von Lampe and J. L. Newell (eds) Criminal Finances and Organising Crime in Europe. (pp.41-66) (Nijmegen, 2003)

${ }^{57}$ M.E. Beare, 'Organised Corporate Criminality: Corporate Complicity in Tobacco Smuggling'. In M. E. Beare (ed.) Critical Reflection on Transnational Organised Crime, Money Laundering, and Corruption. (pp.183-206) (Toronto, 2003)

${ }^{58}$ K. von Lampe, 'Organised Crime Research in Perspective'. In P.C. van Duyne, K. von Lampe and N. Passas (eds) Upperworld and Underworld in Cross-Border Crime. (pp.189-198) (Nijmegen, 2002) p. 196

${ }_{59}$ P.C. van Duyne, 'Introduction: Upper- and Underworld Cross-Border Crime Economy'. In P.C. van Duyne, K. von Lampe and N. Passas (eds) Upperworld and Underworld in Cross-Border Crime. (pp.19) (Nijmegen, 2002) p.5

${ }^{60}$ C. La Vecchia and V. Scarpino, 'Smoking in Italy, 1987-90', 2 Tobacco Control, (1993), pp.231-235

${ }^{61}$ See van Duyne (2003), loc. cit.
} 
Antonopoulos, G. A. (2006) 'Cigarette Smuggling: A Case Study of a Smuggling Network in Greece', European Journal of Crime, Criminal Law and Criminal Justice 